\section{Cueing signals in auditory detection and frequency discrimination experiments*}

\author{
DAVID S. EMMERICH \\ State University of New York at Stony Brook, Stony Brook, New York 11790
}

The effects of presenting a cueing signal during the warning interval initiating a trial were investigated in two-interval forced-choice detection and frequency-discrimination experiments. It was expected that the cueing signal would reduce the uncertainty of $\mathrm{Ss}$ about the stimuli being presented in these experiments. In general, it was found that performance tended to improve as the experiments progressed, both in conditions in which cues were presented and in control conditions in which no cues were presented. The improvement observed in control conditions is not usually found in similar experiments in which cues are not employed. Though performance generally improved, it was found that for some stimulus conditions the cues tended to depress average performance below the level attained without such cues.

Several models of auditory signal detection have been proposed which have some general features in common. These features include a preliminary filter, followed by a nonlinear transformation of the filtered waveform, and a decision process. Experiments have been devised to determine if the performance of human $S s$ is consistent with the predictions of various models with this basic structure.

One approach that has been employed to examine properties of the preliminary filtering performed by the human $S$ involves the introduction of frequency uncertainty into the auditory signal-detection situation. In experiments taking this appraoch, the E typically selects the signal to be presented on a particular trial from a set of two or more sinusoidal signals differing in frequency. Detection performance in this situation is then compared with that obtained when the set of possible signals is restricted to a single sinusoid. Performance decrements due to the frequency uncertainty introduced by $\mathrm{E}$ have helped to characterize the process of frequency selectivity exhibited by $S s$ in this situation. Green (1961) conducied an experiment of this sort in which a particularly wide range of signal frequencies was employed. In one condition of his experiment the range of possible frequencies extended from $500 \mathrm{~Hz}$ to $4,000 \mathrm{~Hz}$. It was found that the effect of this frequency uncertainly was surprisingly small. Only about $3 \mathrm{~dB}$ more signal energy was necessary in order to bring detection performance with frequency uncertainty to the level at tained when only a single signal frequency was used.

Green (1961) suggested that the reason the effects of the frequency uncertainty

\footnotetext{
* This rescarch was supported in part by the Research lioundation of the State of New York.
}

introduced by the $\mathrm{E}$ are typically small in such experiments, may be that $S$ is already rather uncertain about signal frequency, even when only a single frequency is being employed. That is, it may be that the additional uncertainty introduced by the $\mathrm{E}$ is only a relatively minor portion of the frequency uncertainty experienced by Ss in these experiments.

If, as Green suggested, the $S$ in the experiment employing only a single signal frequency is actually very uncertain as to the signal frequency, it is of interest to see if the $E$ can find experimental manipulations that act to reduce the S's uncertainty in this simple situation. If the S's frequency uncertainty can be reduced by certain manipulations, it may be possible to characterize better the nature of this uncertainty. Some recent articles suggest that the $S$ 's frequency uncertainty has several different aspects. Sorkin, Pastore, and Gilliom (1968) presented data that indicate that the $S$ may be able to adjust the bandwidth of his filter (or critical band) as $E$ varies the probability that different signal frequencies will be presented. Henning (1967b) proposed a model of auditory discrimination and detection that incorporates another possible factor in frequency uncertainty. In Henning's model, the center frequency of the S's filter is assumed to vary randomly over time.

If S's filter varies in bandwidth and location, then it is possible that $\mathrm{E}$ can provide information to $S$ that allows more efficient adjustment of the filtering mechanism than is usually the case. Thus, if $S$ is given additional information, it may be possible to reduce his frequency uncertainty, even in the situation in which only a single signal frequency is employed. Shipley (1959) reported that in a two-interval forced-choice experiment in which the signal on a given trial could be of either a high or a low intensity, the probability of detecting a signal was somewaht higher on trials following detection of a high-intensity signal than on trials following detection of a low-intensity signal. Shipley interpreted this result as evidence that the high-intensity signal was a more adequate cue for the $S$ than was the low-intensity signal. Greenberg (1962) investigated the effect of a frequency cue presented just before each trial of a single-interval experiment. The cue employed was a sinusoid with the same parameters as those of the signal that might occur (with probability 0.5 ) during the observation interval. The time interval between presentation of the cue and presentation of the observation interval was systematically varied. The effects of the cue were small in all cases, the largest increment in detection performance being equivalent to that which would be produced by an increment of approximately $0.5 \mathrm{~dB}$ in signal energy. Greenberg pointed out that one reason that the effect of the cue was found to be small may have been that the cue itself was not very detectable. The Ss in the experiment just described were performing at a level such that they would be expected to make the correct response on only about $75 \%$ of the trials.

The first two experiments in the present study were undertaken in order to investigate the effects of a cue of the sort used by Greenberg in a two-interval forced-choice detection paradigm. The intensity of the signal, and the cue intensity relative to the signal intensity were varied. The frequency of the signal employed was different in the two experiments. The third experiment investigated the effects of a cue on performance on a frequency-discrimination task similar to that employed by Henning $(1967 \mathrm{a})$

\section{EXPERIMENT 1}

An examination of the experimental literature concerned with critical bands suggests that frequency uncertainty should be a positive function of signal frequency. In this experiment a relatively low signal frequency, $500 \mathrm{~Hz}$, was employed.

\section{Procedure}

Sinusoidal signals were presented to the Ss in a background of wideband white Gaussian noise by means of headsets employing Telephonics TDH39 earphones. The noise was produced by a Grason-Stadler $455 \mathrm{C}$ noise generator, and was continuously present at a spectral level, $\mathrm{N}_{0}$, of approximately $45 \mathrm{~dB}$ re 0.0002 microbar. The sinusoidal signals were gated without respect to phase, and transients were determined by the response 
Table 1

Proportions of Correct Responses in Experiment 1

\begin{tabular}{|c|c|c|c|c|c|c|c|c|c|c|c|c|}
\hline \multirow[b]{3}{*}{ Subject } & \multicolumn{12}{|c|}{ Conditions } \\
\hline & \multicolumn{3}{|c|}{$\begin{array}{c}\text { No cue; } \\
\text { signal level in } \mathrm{dB}\end{array}$} & \multicolumn{3}{|c|}{$\begin{array}{c}\text { Cue level equal to } \\
\text { signal level; signal } \\
\text { level in } \mathrm{dB}\end{array}$} & \multicolumn{3}{|c|}{$\begin{array}{c}\text { Cue level } 3 \mathrm{~dB} \text { greater } \\
\text { than signal level; signal } \\
\text { level in } \mathrm{dB}\end{array}$} & \multicolumn{3}{|c|}{$\begin{array}{l}\text { Cuc level } 6 \mathrm{~dB} \text { greater } \\
\text { than signal level; signal } \\
\text { level in } \mathrm{dB}\end{array}$} \\
\hline & 8 & 10 & 12 & 8 & 10 & 12 & 8 & 10 & 12 & 8 & 10 & 12 \\
\hline \multicolumn{13}{|c|}{ First Four Sessions of Experiment 1} \\
\hline $\begin{array}{l}1 \\
2 \\
3\end{array}$ & $\begin{array}{l}.570 \\
.705 \\
.570\end{array}$ & $\begin{array}{l}.735 \\
.820 \\
.740\end{array}$ & $\begin{array}{l}.870 \\
.945 \\
.835\end{array}$ & $\begin{array}{l}.605 \\
.730 \\
.590\end{array}$ & $\begin{array}{l}.705 \\
.855 \\
.715\end{array}$ & $\begin{array}{l}.895 \\
.920 \\
.785\end{array}$ & $\begin{array}{l}.616 \\
.688 \\
.583\end{array}$ & $\begin{array}{l}.710 \\
.805 \\
.685\end{array}$ & $\begin{array}{l}.910 \\
.960 \\
.855\end{array}$ & $\begin{array}{l}.655 \\
.710 \\
.570\end{array}$ & $\begin{array}{l}.725 \\
.785 \\
.700\end{array}$ & $\begin{array}{l}.925 \\
.945 \\
.875\end{array}$ \\
\hline \multicolumn{13}{|c|}{ Second Four Sessions of Experiment 1} \\
\hline $\begin{array}{l}1 \\
2 \\
3\end{array}$ & $\begin{array}{l}.655 \\
.750 \\
.640\end{array}$ & $\begin{array}{l}.730 \\
.840 \\
.740\end{array}$ & $\begin{array}{l}.885 \\
.960 \\
.845\end{array}$ & $\begin{array}{l}.710 \\
.760 \\
.710\end{array}$ & $\begin{array}{l}.785 \\
.835 \\
.700\end{array}$ & $\begin{array}{l}.835 \\
.940 \\
.810\end{array}$ & $\begin{array}{l}.665 \\
.725 \\
.600\end{array}$ & $\begin{array}{l}.740 \\
.815 \\
.725\end{array}$ & $\begin{array}{l}.910 \\
.960 \\
.850\end{array}$ & $\begin{array}{l}.695 \\
.690 \\
.690\end{array}$ & $\begin{array}{l}.765 \\
.820 \\
.760\end{array}$ & $\begin{array}{l}.845 \\
.895 \\
.875\end{array}$ \\
\hline \multicolumn{13}{|c|}{ Last Four Sessions of Experiment 1} \\
\hline $\begin{array}{l}1 \\
2 \\
3 \\
\end{array}$ & $\begin{array}{l}.735 \\
.720 \\
.635 \\
\end{array}$ & $\begin{array}{l}.780 \\
.845 \\
.735 \\
\end{array}$ & $\begin{array}{l}.915 \\
.945 \\
.870 \\
\end{array}$ & $\begin{array}{l}.700 \\
.760 \\
.625 \\
\end{array}$ & $\begin{array}{l}.775 \\
.820 \\
.745 \\
\end{array}$ & $\begin{array}{r}.860 \\
.920 \\
.850 \\
\end{array}$ & $\begin{array}{r}.640 \\
.765 \\
.630 \\
\end{array}$ & $\begin{array}{l}.815 \\
.850 \\
.780 \\
\end{array}$ & $\begin{array}{l}.910 \\
.920 \\
.900 \\
\end{array}$ & $\begin{array}{l}.730 \\
.750 \\
.725 \\
\end{array}$ & $\begin{array}{r}.790 \\
.855 \\
.765 \\
\end{array}$ & $\begin{array}{r}.849 \\
.915 \\
.860 \\
\end{array}$ \\
\hline
\end{tabular}

characteristics of the earphones. Three Ss participated at the same time, and all were seated in a single Industrial Acoustics Company sound-attenuating chamber. The earphones of the Ss were connected together in phase and in parallel.

A tone demonstration was provided for the Ss prior to each block of trials. Tone demonstrations consisted of several brief presentations of the sinusoidal signal at an intensity $10 \mathrm{~dB}$ higher than that at which it would be presented during the subsequent block of trials, followed by several brief presentations at the same intensity at which it would be presented during the block of trials.

A two-interval forced-choice (2IFC) detection paradigm was used. Two observation intervals were defined on each trial. During one of these intervals of time the sinusoidal signal was added to the noise background, and during the other interval noise alone was present. The probability that the signal would be presented during the first interval on any given trial was equal to the probability that it would be presented during the second interval (i.e., $0.5)$. The S's task was to indicate the observation interval during which the signal was presented.

Each trial was initiated by a warning light that was illuminated for $200 \mathrm{msec}$. The warning light was followed by a pause of $500 \mathrm{msec}$, the first observation interval $(200 \mathrm{msec})$, another pause of $500 \mathrm{msec}$, the second observation interval $(200 \mathrm{msec})$, a $1,500-\mathrm{msec}$ response interval, a $200-\mathrm{msec}$ feedback interval, and a final pause of $500 \mathrm{msec}$ duration. The observation intervals were each indicated by the illumination of a light. During the feedback interval, one of the observation interval lights was illuminated again in order to indicate the interval during which the signal had been presented on that trial.
The Ss communicated their decisions as to which interval had contained the signal by pressing one of two buttons during the response interval. These button presses were recorded by electromechanical counters.

Three young men with clinically normal hearing were paid to participate in this experiment. None of these men had been Ss before in an auditory experiment. An experimental session for these Ss lasted approximately $1.5 \mathrm{~h}$. Each session was divided into three segments which were separated by a rest period of 5 to $10 \mathrm{~min}$. Each segment consisted of a 20-trial practice block followed by an 80-trial data block and two 60-trial data blocks. These four blocks of trials were separated by rest periods of approximately 2 min duration.

Prior to the experiment the Ss were given several sessions of practice. This permitted the Ss to become familiar with the 2IFC paradigm and the experimental conditions, and permitted $\mathrm{E}$ to choose signal levels such that the detection task was neither too difficult nor too easy for the Ss.

Three different signal levels were employed. The values of $10 \log \left(E / N_{o}\right)$ used, where $E$ is the signal energy and $N_{o}$ is the spectral level of the noise, were 8,10 , and 12 . The signal duration was $200 \mathrm{msec}$.

In each session of the experiment the highest value of $10 \log \left(E / N_{0}\right)$ was used during the first segment of the session, the next highest value during the next segment of the session, and the lowest value during the last segment of the session. During most sessions of the experiment a cue was presented to the $S$ at the beginning of each trial. The cue was a sinusoid of the same frequency and duration as the signal, and was presented along with the warning light. The cue level was varied during the experiment. The cue level was the same as the signal level, $3 \mathrm{~dB}$ greater than the signal level, or $6 \mathrm{~dB}$ greater than the signal level.

The relationship of the cue level to the signal level was kept constant throughout an entire experimental session. Thus, if the cue level was $3 \mathrm{~dB}$ greater than the signal level, the $10 \log \left(E / N_{o}\right)$ of the cue would be 15 during the first segment of the session, 13 during the next segment of the session, and 11 during the final segment of the session.

Experiment 1 consisted of 12 experimental sessions. A random

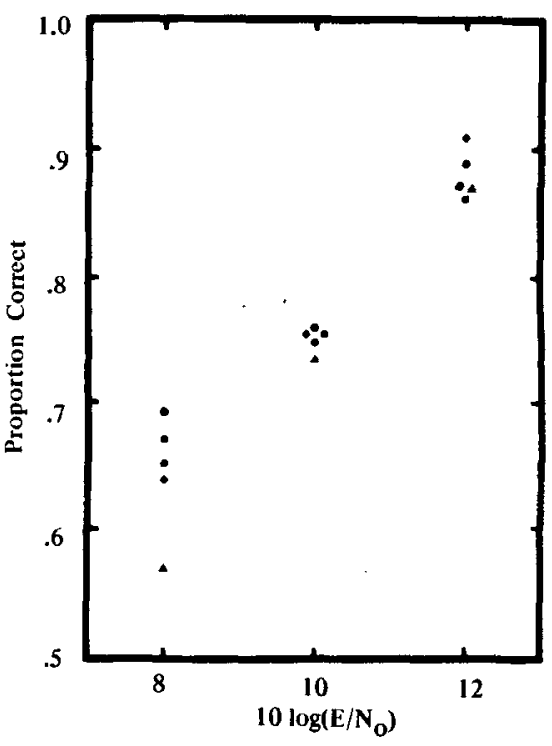

Fig. 1. Proportions of correct responses obtained in Experiment 1 from $S 1$. Triangles represent proportions obtained with no cue in the first third of the experiment. Circles represent mean proportions obtained with no cue. Squares, diamonds, and hexagons represent mean proportions obtained with cue intensity equal to, $3 \mathrm{~dB}$ greater than, and $6 \mathrm{~dB}$ greater than signal intensity, respectively. 


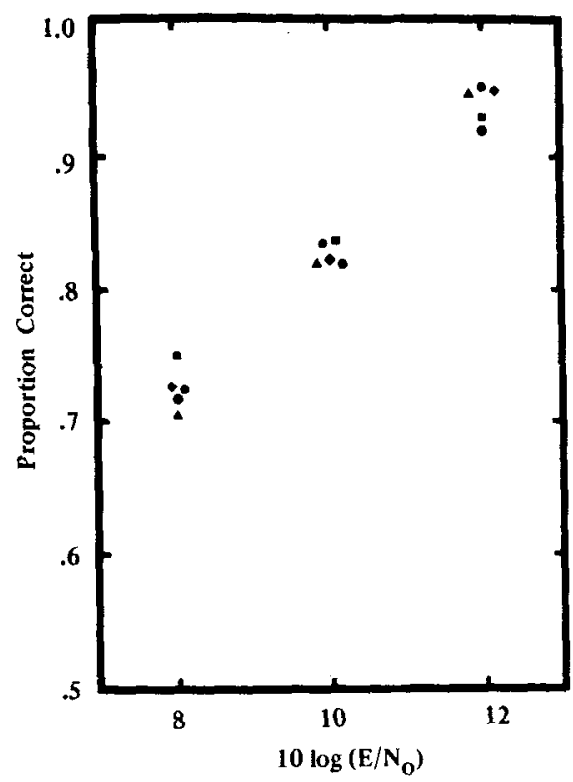

Fig. 2. Same as Fig. 1, for $\mathrm{S} 2$.

permutation of the four conditions (no cue; cue level the same as, $3 \mathrm{~dB}$ greater than, or $6 \mathrm{~dB}$ greater than signal level) was selected in order to determine the stimulus situation for Sessions 1-4. Different random permutations of the conditions were selected for Sessions 5-8 and Sessions 9-12.

\section{Results and Discussion}

The proportions of trials on which the correct decision was made by each $S$ in each experimental condition in each third of the experiment are presented in Table 1 . Each proportion in the table is based upon a total of 200 trials except in those rare instances in which the $S$ did not complete a response during the response interval. The averages across sessions of these proportions for each $S$ and experimental condition are presented in Figs. 1-3. The proportions for the first session in which no cue was presented may also be found in Figs. 1-3. The latter values were included in order that the reader could evaluate more easily the way in which performance changed in this condition over the course of the experiment.

Several aspects of the data in Table 1 seem worthy of comment. Perhaps the most obvious feature of the data is the large degree of variability, both between $\mathrm{Ss}$ and within the same $S$ over sessions. Performance tended to improve in the different conditions throughout the experiment, particularly for the lower signal levels. Continued improvement over such a long period of time is not often reported in auditory experiments in which a forced-choice procedure is used, especially when the Ss are well-practiced before the beginning of the experiment.
Another interesting feature of the data is the lack of a monotonic relationship between cue intensity and detection performance. Prior to the experiment it was anticipated that in the range of cue intensities employed, any cue would be at least as effective as no cue, and that more intense cues would reduce uncertainty (i.e., improve detection performance) by a greater amount than would less intense cues. At best, it can be said that the data presented in Table 1 provide little support for such a hypothesis.

Most of the differences between entries in Table 1 for a signal of a given intensity presented (to a particular $\mathbf{S}$ ), with and without a cue, tend to be rather small. If binomial variance is assumed, it is a straightforward matter to determine the amount of difference between two such entries needed to attain statistical significance. For example, if an entry is 0.95 , a corresponding entry must differ from it by approximately 0.03 for the difference to be statistically significant at the 0.05 level. If an entry is 0.60 , the difference must be approximately 0.07 to attain the 0.05 level of significance.

The tendency for performance to improve, which was mentioned above, and the variability of the data make the evaluation of the effects of the cues difficult. Another factor of possible importance is that the $S$ s received feedback on each trial and thus were able to modify their behavior on the basis of this information as well as on the basis of the information carried by the cue. More will be said in this regard later; for the present discussion the data will be taken at face value.

An examination of Figs. 1-3 indicates that if mean performance in the cue conditions is compared with mean initial performance (represented by triangles) in the no-cue conditions, performance with cues is generally found to be better. Cues seem to be most useful at the lowest signal intensity used in the experiment. Such results seem quite plausible: presumably the greater the detectability of the signal, the less the uncertainty in the situation, and hence the less useful a cue would be in reducing uncertainty.

If, however, comparisons are made with the mean proportions in the no-cue conditions, a somewhat different picture emerges, since the performance improved in these conditions as the experiment progressed. These comparisons suggest that the cues tend to be slightly helpful when signals of the lowest intensity are to be detected, tend to be of little or no use when the middle signal intensity is used, and may actually tend to degrade performance when the highest signal

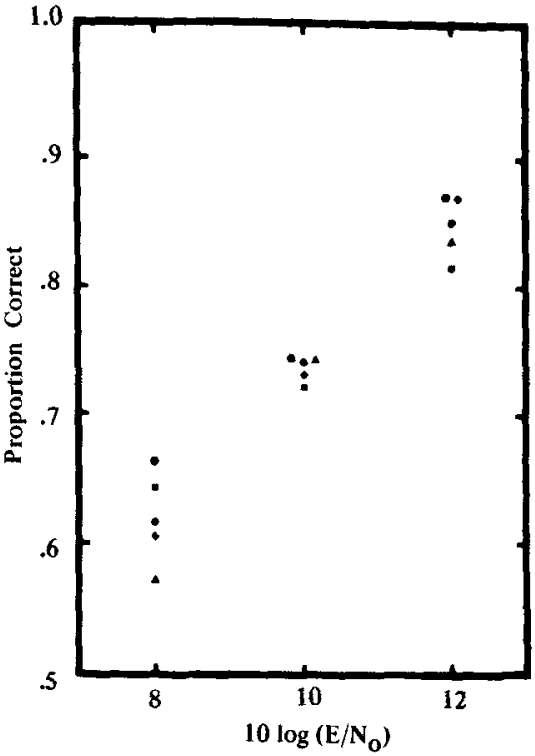

Fig. 3. Same as Fig. 1, for S 3.

intensity is employed. Each point in Figs. 1-3 is based upon 600 trials.

The middle signal intensity in the present experiment is approximately the same as that employed by Greenberg (1962). As was mentioned earlier, Greenberg found that cueing had only a slightly positive effect on detection performance.

\section{EXPERIMENT 2}

In this experiment the effects of cueing signals of the sort employed in Experiment 1 were investigated for the case in which the frequency of the signal to be detected was $4,000 \mathrm{~Hz}$. The experimental literature on critical bands suggests that frequency uncertainty should be greater with a $4,000-\mathrm{Hz}$ signal than with the $500-\mathrm{Hz}$ signal used in Experiment 1.

\section{Procedure}

As in Experiment 1, the Ss were three young men with clinically normal hearing who were paid for their participation. One of the Ss had participated in Experiment 1.

In Experiment 2 the signal frequency was $4,000 \mathrm{~Hz}$, and the values of $10 \log \left(E / N_{0}\right)$ used were 13,15 , and 17 . In other respects the procedure employed in Experiment 2 was essentially the same as that employed in Experiment 1.

\section{Results and Discussion}

The proportions of correct responses made by each $S$ in each experimental condition in each third of the experiment are presented in Table 2. The averages of these proportions across sessions for the three $\mathrm{Ss}$ are presented in Figs. 4-6. The data in Table 2 exhibit marked variability both between $S s$ and within $S$ over 
Table 2

Proportions of Correct Responses in Experiment 2

\begin{tabular}{|c|c|c|c|c|c|c|c|c|c|c|c|c|}
\hline \multirow[b]{3}{*}{ Subject } & \multicolumn{12}{|c|}{ Conditions } \\
\hline & \multicolumn{3}{|c|}{$\begin{array}{c}\text { No cue; } \\
\text { signal level in } \mathrm{dB}\end{array}$} & \multicolumn{3}{|c|}{$\begin{array}{c}\text { Cue level equal to } \\
\text { signal level; signal } \\
\text { level in dB }\end{array}$} & \multicolumn{3}{|c|}{$\begin{array}{c}\text { Cue level } 3 \mathrm{~dB} \text { greater } \\
\text { than signal level; signal } \\
\text { level in } \mathrm{dB}\end{array}$} & \multicolumn{3}{|c|}{$\begin{array}{c}\text { Cue level } 6 \mathrm{~dB} \text { greater } \\
\text { than signal level; signal } \\
\text { level in } \mathrm{dB}\end{array}$} \\
\hline & 13 & 15 & 17 & 13 & 15 & 17 & 13 & 15 & 17 & 13 & 15 & 17 \\
\hline \multicolumn{13}{|c|}{ First Four Sessions of Experiment 1} \\
\hline $\begin{array}{l}1 \\
2 \\
3\end{array}$ & $\begin{array}{l}.555 \\
.710 \\
.785\end{array}$ & $\begin{array}{l}.700 \\
.825 \\
.814\end{array}$ & $\begin{array}{l}.745 \\
.945 \\
.870\end{array}$ & $\begin{array}{l}.530 \\
.800 \\
.754\end{array}$ & $\begin{array}{l}.575 \\
.885 \\
.880\end{array}$ & $\begin{array}{l}.685 \\
.935 \\
.925\end{array}$ & $\begin{array}{l}.560 \\
.695 \\
.710\end{array}$ & $\begin{array}{l}.770 \\
.835 \\
.824\end{array}$ & $\begin{array}{l}.795 \\
.880 \\
.925\end{array}$ & $\begin{array}{l}.685 \\
.734 \\
.715\end{array}$ & $\begin{array}{l}.765 \\
.800 \\
.800\end{array}$ & $\begin{array}{l}.850 \\
.910 \\
.865\end{array}$ \\
\hline \multicolumn{13}{|c|}{ Second Four Sessions of Experiment 2} \\
\hline $\begin{array}{l}1 \\
2 \\
3\end{array}$ & $\begin{array}{l}.580 \\
.775 \\
.640\end{array}$ & $\begin{array}{l}.665 \\
.840 \\
.825\end{array}$ & $\begin{array}{l}.835 \\
.965 \\
.950\end{array}$ & $\begin{array}{l}.660 \\
.725 \\
.700\end{array}$ & $\begin{array}{l}.640 \\
.870 \\
.845\end{array}$ & $\begin{array}{l}.825 \\
.955 \\
.955\end{array}$ & $\begin{array}{l}.670 \\
.720 \\
.675\end{array}$ & $\begin{array}{l}.810 \\
.860 \\
.865\end{array}$ & $\begin{array}{l}.865 \\
.934 \\
.935\end{array}$ & $\begin{array}{l}.615 \\
.790 \\
.705\end{array}$ & $\begin{array}{l}.685 \\
.844 \\
.770\end{array}$ & $\begin{array}{l}.835 \\
.955 \\
.945\end{array}$ \\
\hline \multicolumn{13}{|c|}{ Last Four Sessions of Experiment 2} \\
\hline $\begin{array}{l}1 \\
2 \\
3 \\
\end{array}$ & $\begin{array}{r}.635 \\
.682 \\
.685 \\
\end{array}$ & $\begin{array}{l}.775 \\
.860 \\
.825 \\
\end{array}$ & $\begin{array}{l}.870 \\
.955 \\
.925 \\
\end{array}$ & $\begin{array}{l}.630 \\
.785 \\
.720 \\
\end{array}$ & $\begin{array}{l}.735 \\
.850 \\
.835 \\
\end{array}$ & $\begin{array}{l}.935 \\
.945 \\
.940 \\
\end{array}$ & $\begin{array}{l}.615 \\
.750 \\
.770 \\
\end{array}$ & $\begin{array}{l}.765 \\
.895 \\
.845 \\
\end{array}$ & $\begin{array}{l}.810 \\
.959 \\
.935\end{array}$ & $\begin{array}{l}.610 \\
.677 \\
.745 \\
\end{array}$ & $\begin{array}{l}.680 \\
.800 \\
.825 \\
\end{array}$ & $\begin{array}{l}.820 \\
.935 \\
.885 \\
\end{array}$ \\
\hline
\end{tabular}

sessions, as did the data of Experiment 1. Again, performance in the different conditions tends to improve over sessions. Also as in Experiment 1, the data displayed in Figs. 4-6 show that mean performance with cues is generally better than initial performance without cues. Similarly, when the same comparisons are made with mean performance in the no-cue conditions, the effects of the cues are found to be less pronounced. Again there seems to be no monotonic relationship between cue

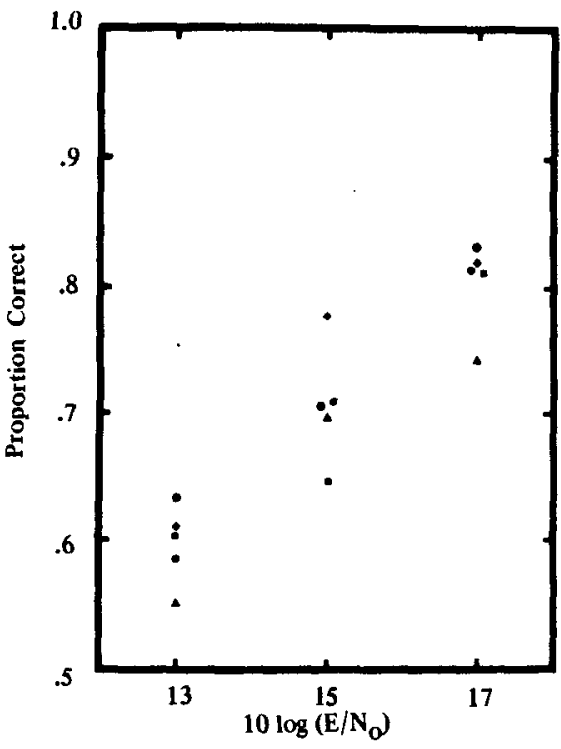

Fig. 4. Proportions of correct responses obtained in Experiment 2 from $S 1$. Triangles represent proportions obtained with no cue in the first third of the experiment. Circles represent mean proportions obtained with no cue. Squares, diamonds, and hexagons represent mean proportions obtained with cue intensity equal to, $3 \mathrm{~dB}$ greater than, and $6 \mathrm{~dB}$ greater than signal intensity, respectively. intensity and performance, and there is the suggestion that some cue conditions may degrade performance.

\section{EXPERIMENT 3}

In this experiment the usefulness of a cueing signal presented before each trial was investigated in a different experimental situation. In Experiments 1 and 2 a detection task was employed; in Experiment 3 a frequency-discrimination task was employed. In addition, the experimental conditions in Experiment 3 were presented in such a way that if the improvements in performance across sessions observed earlier also occurred in Experiment 3 , more information about the basis of these improvements could be obtained.

\section{Procedure}

Ss were given a frequency-discrimination task similar to that employed by Henning (1967a). In order to facilitate comparisons with Henning's data, the spectral level, $\mathrm{N}_{\mathrm{o}}$, of the noise employed in Experiment 3 was approximately $32 \mathrm{~dB}$ re 0.0002 microbar. A Grason-Stadler 829E electronic switch was used to gate the sinusoidal signals with a $10-\mathrm{msec}$ rise/fall time. The intervals of time defining a trial in the third experiment were of the same duration as those used in Experiments 1 and 2 . However, in Experiment 3, each of the two observation intervals contained a signal on every trial. One of the two signals presented on every trial had a frequency of $996 \mathrm{~Hz}$ and the other had a frequency of $1,004 \mathrm{~Hz}$. The S's task was to indicate which observation interval contained the higher-frequency tone. The probability that the higher-frequency tone would be presented during the first observation interval on any given trial was 0.5 .

Two young men with clinically normal hearing were paid to participate in the experiment. Neither of these men had previously participated in an auditory experiment. An experimental session for these Ss lasted approximately $1 \mathrm{~h}$. Each session was divided into three segments which were separated by a rest period of $5-10$ min. Each segment consisted of a 20-trial practice block (or two such blocks if the Ss so requested) followed by two 50-trial data blocks. These blocks were separated by rest periods of approximately 2 min duration.

During the first segment of an experimental session, $10 \log \left(E / N_{0}\right)$ was 20 for each of the two signals. During the next segment of the session, $10 \log \left(E / N_{o}\right)$ was 15 for both signals, and during the final segment, $10 \log \left(E / N_{0}\right)$ was 10 for both signals.

During some of the experimental

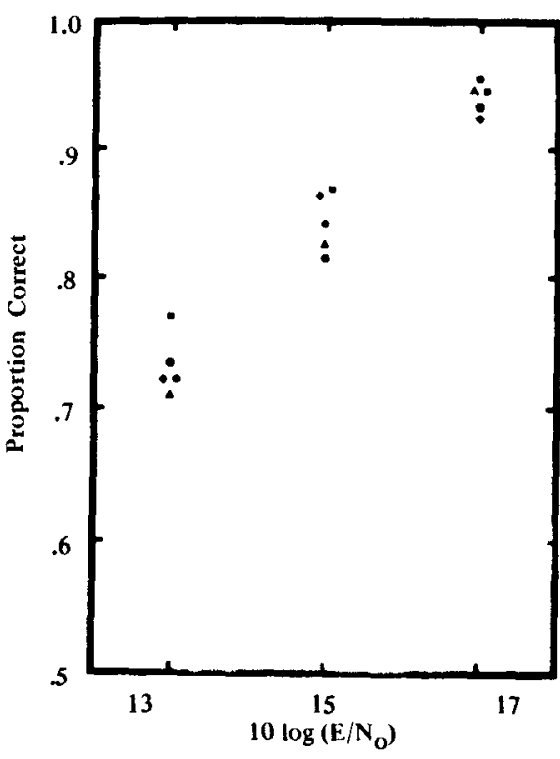

Fig. 5. Same as Fig. 4, for $S 2$. 


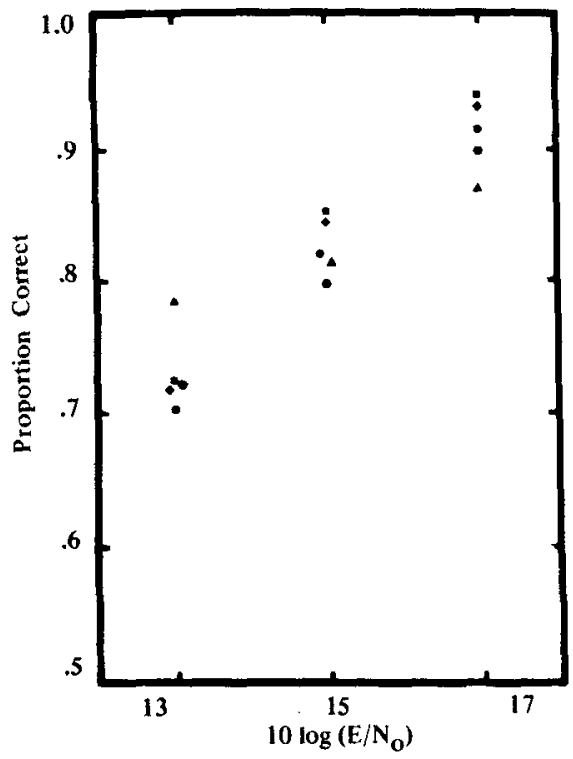

Fig. 6. Same as Fig. 4, for S 3 .

sessions a sinusoidal cue was presented on each trial at the same time that the warning light was illuminated. The value of $10 \log \left(E / N_{0}\right)$ associated with the cue was always 15 . The frequency of the cue was fixed for an entire session.

Before each block of trials the sinusoids to be used were demonstrated to the $\mathrm{Ss}$ in the manner described earlier.

Prior to the experiment the Ss were given two sessions of practice with no cue being presented. Performance had stabilized by the end of the second practice session. Then three experimental sessions were conducted, again with no cue being presented. Next, two sessions of practice and three experimental sessions were given in which a $1,000 \mathrm{~Hz}$ cue was presented during the warning interval on each trial. Then two practice sessions and threc experimental sessions were conducted with a cue frequency of $990 \mathrm{~Hz}$. Last of all, a final two practice sessions and three experimental sessions were conducted in the no-cue condition.

\section{Results and Discussion}

The proportions of correct responses attained in each of the experimental condilions are presented in Tables 3 and 4 for $S 1$ and $S 2$, respectively, Each proportion in these tables is based upon 300 trials. The four rows of these tables are arranged in the order in which the conditions were presented to the Ss: the no-cue condition was presented firsl, followed by the $1,000 \cdot 1 \mathrm{z}$ cue condition, the $990-\mathrm{Hz}$ cue condition, and finally by a return to the no-cue condition.

If performance in the $1,000-\mathrm{Hz}$ cue condition is compared with initial performance in the no-cue condition, it can be seen from Tables 3 and 4 that, except for the greatest signal intensity for $S 2$, the $1,000 \cdot \mathrm{Hz}$ cue did not facilitate discrimination performance. In fact, the presentation of this cue $500 \mathrm{msec}$ before the first observation interval tended to degrade discrimination performance. The Ss had a ready explanation for this fact. The $1,000-\mathrm{Hz}$ cue was midway in frequency between the $996-\mathrm{Hz}$ and $1,004-\mathrm{Hz}$ signals that were to be discriminated. The Ss reported that they attempted to compare the signals to the sinusoidal cue in order to determine which was the higher-frequency signal. Such comparisons were, not surprisingly, more difficult than the comparisons between the $996-\mathrm{Hz}$ and $1,004-\mathrm{Hz}$ signals in the initial no-cue condition, and performance suffered.

When a $990-\mathrm{Hz}$ cue was employed, however, the Ss were able to improve their discrimination performance at all signal intensities. S 2 in particular showed rather sizeable gains in proportion of correct responses. Interestingly enough, when this cue was removed and the no-cue condition was reinstated. the $S s$ were able to maintain an improved level of performance relative to their initial performance in the no-cue condition.

\section{GENERAL DISCUSSION}

In Experiments 1 and 2 the average level of detection performance tended to go up as the experiment progressed. Whitmore, Ermey, and Williams (1968) have reported improvements in performance in the $2 \mathrm{IFC}$ detection situation over an even longer period of time. They found improvements, after giving $S s$ an interpolated rating task, over a 5 -month period of time. These Es point out that practice effects in 2IFC experiments are generally found to have brought perfomance to an asymplote within 1,000 trials or so. (Ss in Experiments 1 and 2 received over 1,500 trials of practice before the experiments began.)

Improvements in performance in Experiments 1 and 2 occurred both in conditions in which cucs were employed and in conditions in which cues were not employed. In view of the fact that long-term improvements are not typically observed in detection experiments in which cues are not employed, it seems reasonable to assume that cues had effects in these experiments not only in conditions in which they were presented, but also more long-lasting effects that enabled $S s$ to perform more efficiently in no-cue conditions. The finding that $S$ s could maintain improved discrimination performance in Experiment 3 after the 990-Hz cue was removed, also lends itself
Table 3

Proportion of Correct Responses for Subject 1 in Experiment 3

\begin{tabular}{lccc}
\hline & \multicolumn{3}{c}{ Signal Level in $\mathrm{dB}$} \\
\cline { 2 - 4 } Condition & 10 & 15 & 20 \\
\hline No cue & .600 & .830 & .950 \\
$1,000-1$ z cue & .567 & .760 & .933 \\
$990-\mathrm{Hz}$ cue & .630 & .873 & .977 \\
No cue & .657 & .853 & .983 \\
\hline
\end{tabular}

Table 4

Proportion of Correct Responses for Subject 2 in Experiment 3

\begin{tabular}{llll}
\hline & \multicolumn{3}{c}{ Signal Level in $\mathrm{dB}$} \\
\cline { 2 - 4 } Condition & 10 & 15 & 20 \\
\hline No cue & .533 & .727 & .817 \\
$1.000-\mathrm{Hz}$ cue & .493 & .703 & .897 \\
$990-\mathrm{Hz}$ cue & .570 & .790 & .920 \\
No cue & .613 & .783 & .887 \\
\hline
\end{tabular}

to this interpretation. Similarly, the fact that performance had stabilized in the no-cue condition when it was initially presented in Experiment 3, and that performance tended to worsen when the $1,000-\mathrm{Hz}$ cue was introduced, suggests that the improvements observed with the subsequent introduction of the $990-\mathrm{Hz}$ cue and reintroduction of the no-cue condition were not due to additional practice in the discrimination situation alone.

The variability of the data obtained in Experiments 1 and 2 makes statements about the relative effectiveness of cues as a function of the signal frequency employed rather hazardous. It is interesting to note that there is evidence in both of these experiments (as well as in Experiment 3) that the presence of a cue in a session can lead to detection performance that is poorer than it would have been without the cue. It seems surprising that a cue presented at the beginning of a trial could degrade performance and yet not be ignored by $S s$ who received trial-by-trial feedback. Perhaps with even more experience in the situation $S$ s would have learned to disregard cues when their effects were not beneficial. Other Es have also reported instances in which cues have degraded performance. Sorkin (1965) found that cues degraded performance when the signal was highly detectable, and facilitated performance when the signal was difficult to detect. Taylor and Clarke (1968) found that the effects of cues depended upon frequency: detection performance was facilitated for low-frequency signals, and degraded for high-frequency signals. In both of these studies a procedure quite different from that employed in Experiments 1 and 2 of the present study was used: the signal was presented monaurally in a noise background, while the cue was presented 
simultaneously (and unmasked) to the other ear.

In attempting to understand the relative difficulty Ss had in certain cue conditions in Experiments 1 and 2, the Ss' verbal reports were of interest. For the combinations of highly detectable cues and more intense signals, Ss often reported hearing signals in both observation in tervals on most trials. The task of the Ss then became that of deciding which of two signals was the more intense, and they found this task to be a difficult one. Such verbal reports were reminiscent of the discussion by Bos and de Boer (1966) of Fletcher's band-narrowing experiments in terms of the stimulus properties of narrow bands of noise. These authors suggest that the inherent fluctuations of intensity of narrow-band noise can limit the ability of Ss to detect signals whose frequencies fall within that band. Perhaps analogous processes took place in Experiments 1 and 2 and can account for some of the observed small changes in detection performance. It is possible that the use of cueing signals enabled the Ss to narrow their critical bands. For weak signals (and hence for relatively weak cues, since in these experiments cue intensity was adjusted relative to signal intensity) such narrowing presumably would act to improve detection performance. If the critical bands of Ss are already narrower when higher intensity signals are being presented, however, it is possible that the presentation of cues could induce $S$ s to make their critical bands too narrow (due to the properties of narrow-band noise discussed by Bos and de Boer) for most efficient performance.

The improvements in frequency. discrimination performance observed in Experiment 3 are also consistent with the notion of a critical band which can be narrowed. Since the signal intensities employed in Experiment 3 (and in comparable conditions of Henning, 1967a) are much larger than those employed in Experiments 1 and 2, fluctuations of noise in a narrow critical band should be a less important factor in this experiment.

Swets (1963) reviews a number of studies which indicate that $S$ s are able to adjust their frequency selectivities as various aspects of the experimental situation are changed. This $\mathrm{E}$ is not familiar with any studies showing directly that the critical bandwidth is narrower for higher-intensity than for lower-intensity signals, however. (Bourbon, Evans, and Deatherage, 1968, have found the critical bandwidth to be narrower for higher levels of masking noise.)

\section{REFERENCES}

BOS, C. E., \& de BOER, E. Masking and discrimination. Journal of the Acoustical Society of America, 1966, 39, 708-715.

BOURBON, W. T., EVANS, T. R., \& DEATHERAGE, B. H, Effects of intensity on "critical bands" for tonal stimuli as determined by band limiting. Journal of the Acoustical Society of America, 1968, 43, 56-59.

GREEN, D. M. Detection of auditory sinusoids of uncertain frequency. Journal of the Acoustical Society of America, 1961, 33, 897-903.

GREENBERG，G. Z. Cueing signals and frequency uncertainty in auditory detection. Technical Report No. ESD-TDR-62-38, 1962, Hearing and Communication Laboratory, Indiana University.

HENNING, G. B. Frequency discrimination in noise. Journal of the Acoustical Society of America, 1967a, 41, 774-777.

HENNING, G. B. A model for auditory discrimination and detection. Joumal of the Acoustical Society of America, 1967b, 42, 1325-1334.

SHIPLEY, E. F. Cueing as a determiner of apparent variability in sensitivity. Journal of the Acoustical Society of America, 1959, 31, 834. (Abstract)

SORKIN, R. D. Uncertain signal detection with simultaneous contralateral cues. Journal of the Acoustical Society of America, 1965, 38, 207-212.

SORKIN, R. D., PASTORE, R. E., \& GILLIOM, J. D. Signal probability and the listening band. Perception \& Psychophysics, 1968, 4, 10-12.

SWETS, J. A. Central factors in auditory frequency selectivity. Psychological Bulletin, $1963,60,429-440$

TAYLOR, M. M., \& CLARKE, D. P. J. Monaural detection with contralateral cue (MDCC): Signal bandwidth and frequency. Journal of the Acoustical Society of America, 1968, 44, 370. (Abstract)

WHITMORE, J. K., ERMEY, H. L., \& WILLIAMS, P. I. Some results bearing on the stability of psychometric data. Joumal of the Acoustical Society of America, 1968, 44, 370 . (Abstract)

(Accepred for publication May 15, 1970.) 